(5) The direction of migration of the colored ions shows that the ruthenium is present in the negative ion, and in that alone.

(6) It will be seen from Table I, that the values for the ruthenium salt are uniformly about io per cent. greater than those for the platinum salt. It is evident, therefore, that the dissociation relations are entirely similar.

\title{
THE ACTION OF FUMING SULPHURIC ACID UPON ISO- AMYL CHLORIDE.
}

BY R. A. WORSTALl.

Received June $24,2903$.

SOME years ago, while the author was engaged upon an investigation of aliphatic sulphonic acids, some preliminary work was done upon the products of the reaction between isoamyl chloride and fuming sulphuric acid. It was the author's intention to make an extended study of the action of sulphuric acid of various degrees of concentration upon different alkyl haloids, but owing to pressure of other work this investigation was dropped, and neither the opportunity nor the facilities have since been available for completing this work. As it does not seem probable that opportunity will be afforded for any further work along this line, it may not be amiss to publish the results of the investigation so far as it was carried.

The following is a brief résumé of the literature upon the subject of the reactions between sulphuric acid and alkyl haloids. Williamson, ${ }^{1}$ by the action of sulphuric anhydride upon ethyl chloride, obtained chlorethyl sulphuric acid, a heavy oil, decomposed by water into hydrochloric acid, sulphuric acid and ethyl sulphuric acid. Methyl chloride gave a similar result. By the action of chlorsulphuric acid upon the alcohols, the same compounds resulted.

Oppenheim ${ }^{2}$ states that amyl chloride with concentrated sulphuric acid gave amyl sulphuric acid, and that all alkyl chloricles, by similar treatment, lose hydrochloric acid and form alkyl sulphuric acids. The same author, ${ }^{3}$ by acting upon ethylene chloride and its homologues with concentrated sulphuric acid in sealed

\footnotetext{
1 J. prakt. Chem., 73,73.

2 Am. Chem. J., 6, 353.

3 Ber, d. chem. Ges., 2, 212.
} 
tubes at $130^{\circ} \mathrm{C}$, obtained decomposition into carbon, sulphur dioxide and hydrochloric acid. No action was apparent at crdinary temperatures.

Wroblewsky ${ }^{1}$ found that sulphuric anhydride with ethylene bromide separated bromine and hydrobromic acid and gave bromethyl sulphonic acid, $\mathrm{C}_{2} \mathrm{H}_{4} \bigcup_{\mathrm{SO}_{2} \mathrm{OH}}^{\mathrm{Br}}$, from which the barium salt was obtained. Ethyl iodide with sulphuric anhydride gave ethyl sulphonic acid.

Purgold, ${ }^{2}$ by the action of sulphuric anhydride on ethyl chloride, obtained chlorethyl sulphate, chlorethyl sulphonic acid, and oxyethyl sulphonchloride. Armstrong ${ }^{3}$ studied the action of sulphuric anhydride on chloroform, carbon tetrachloride and carbon hexachloride, obtaining chlorcarbonic and chlorsulphuric acids.

For the sulphonation of anryl chloride, 30 grams of isoamyl chloride were added gradually to 60 grams fuming sulphuric acid, and the mixture kept cool. Heat was generated with slight evolution of sulphur dioxide. When the reaction was complete, the solution was poured into water and the milky liquid extracted three times with ether. The acid solution was neutralized with barium carbonate and filtered. The filtrate was evaporated to dryness. A white salt was left, which was very deliquescent and which darkened somewhat at the temperature of the steam-bath. The salt was extracted with hot 90 per cent. alcohol and filtered. A large excess of ether in the filtrate precipitated a flocculent, white barium salt, the precipitation not being complete. This salt was analyzed after washing with ether and drying, and found to be impure, containing barium chloride.

The sulphonation was repeated, using 50 grams of isoamyl chloride and 200 grams of fuming sulphuric acid. The reaction mixture was poured into water and this solution extracted three times with ether. The ether solution was washed and evaporated. The residue of 12 grams was a red, oily liquid of a disagreeable odor, and was not further investigated. The water solution was neutralized with barium carbonate, filtered, the filtrate evaporated to a small volume, and an equal volume of 90 per cent. alcohol added. This solution was then evaporated to half its volume and

1 Zlschr. Chem. (1868), p. $5^{6} 3$

2 Ber. d. chem. Ges., 6, 502.

a J.prakt. Chem. [2], 244. 
allowed to stancl. On cooling, beautiful, needle-like crystals, nearly an inch long, separated. These were removed and dried, first between filter-paper, then by standing in a desiccator over sulphuric acid. After standing in the desiccator for a day, the crystals began to whiten and crumble, showing that they were losing water of crystallization. The salt was, therefore, recrystallized from 60 per cent. alcohol and dried between filter-paper. In all, about 40 grams of this salt were obtained.

Analysis of the crystallized salt gave the following results: For moisture, I.I 218 grams lost 0.0824 gram at $100^{\circ}$, equivalent to 7.34 per cent. $\mathrm{H}_{2} \mathrm{O} . \quad\left(\mathrm{C}_{5} \mathrm{H}_{10}<\mathrm{SO}_{3}\right)_{2} \mathrm{Oa} \cdot 2 \mathrm{H}_{2} \mathrm{O}$ should concain 7. Io per cent. $\mathrm{H}_{2} \mathrm{O}$.

The salt dried at $100^{\circ}$ gave the following figures :

$$
\begin{aligned}
& \text { Calculated for } \\
& \left(\mathrm{C}_{5} \mathrm{H}_{10}<\mathrm{SO}_{3}\right)_{2} \mathrm{Ba} \text {. Found. } \\
& \text { Barium ............. } 29.09 \quad 29.05 \\
& \text { Sulphur ............ I } 3.58 \quad 13.98
\end{aligned}
$$

Even the last crystals from the mother-liquor gave no test for chlorine, proving that no chlorsulphonic acid was formed. $\left(\mathrm{C}_{3} \mathrm{H}_{10}<\mathrm{SO}_{3}\right)_{2} \mathrm{Ba}$ and $\left(\mathrm{SO}_{2}<\mathrm{OC}_{5} \mathrm{H}_{11}\right)_{2} \mathrm{Ba}$ are isomers. The latter is known to crystallize with $2 \mathrm{H}_{2} \mathrm{O}$. The former has been reported anhydrous. A concentrated solution of the salt was acidified and boiled with dilute hydrochloric acid. It developed no pink color, no precipitate and no odor of fusel oil. The lead salt was prepared, decomposed by hydrogen sulphide and the free acid boiled. It gave, after long boiling, only a faint test for sulphuric acid. Some isoamyl sulphate was prepared from isoamyl alcohol and concentrated sulphuric acid, and the barium salt formed. The aqueous solution of the latter, even when dilute, when acidified with hydrochloric acid and boiled, gave a pink color, the odor of fusel oil, and a precipitate of barium sulphate. Hence there seemed no doubt that the compound described was barium oxyisoamyl sulphonate, and that it crystallizes with two molecules of water. Mewes ${ }^{1}$ has shown that ethyl sulphate, by the action of fuming sulphuric acid, is converted into oxyethyl sulphonic acid. Hence it is possible that the first product of the reaction between isoamyl chloride and fuming sulphuric acid is isoamyl sulphate, and that this, by further action, is converted into the 1 Ann. Chem. (Liebig), 143, Ig6. 
oxysulphonic acid. There is, however, no experimental evidence to prove this.

Chicago Varnish Co.,

ChICAGo, June, 1903.

[CONTRIbUtion From the Havemeyer LAboratories of Columbia UniVERSITY, NO. 86.]

\section{3,5-BIBROM-2-AMINOBENZOIC ACID : ITS NITRILE AND THE SYNTHESIS OF QUINAZOLINES FROM THE LATTER. ${ }^{1}$}

By MaRston Taylor Bogert and William Flowers HaNd.

Received July 25. 1903.

AtTEMPTS to brominate nitrites have usually resulted unsuccessfully, and the bromination of anthranilic acid has given only tribromaniline. By the use of the calculated amount of nascent bromine, however, we have succeeded in introducing two atoms of bromine, not only into the molecule of anthranilic acid, but also into that of its nitrile, the brominating agent being an aqueous solution of potassium bromide and bromate, in the proportion of five molecules of the former to one of the latter, which, upon acidifying, liberates exactly 3 molecules of bromine, according to the following equation:

$$
5 \mathrm{KBr}+\mathrm{KBrO}_{3}+6 \mathrm{HCl}=3 \mathrm{Br}_{2}+6 \mathrm{KCl}+3 \mathrm{H}_{2} \mathrm{O} \text {. }
$$

A standard solution of bromide and bromate, I cc. of which, upon being acidified, liberated 0.0800 gram of bromine, gave very satisfactory results.

With both anthranilic acid and its nitrile, the bromine entered in the ortho-para positions with reference to the amino group, giving 3,5-bibrom-2-aminobenzoic acid and its nitrile, from which, by elimination of the amino group, 3,5-bibrombenzoic acid and its nitrile were obtained. This elimination of the amino group was accomplished with the greatest difficulty, the yield of the bibrombenzoic compound being small.

The bibromanthranilic nitrile we have converted into quinazolines and thioquinazolines by the use of the methods previously reported by us, ${ }^{2}$ the equations being as follows :

1 Read at the cleveland meeting of the American Chemical Society, June $30,1903$.

2 This Journal, 24, $1031 ; 25,372$. 